\title{
Evaluation of the Prevalence of Urinary Incontinence Symptoms in Adolescent Female Soccer Players and their Impact on Quality of Life
}

\author{
Eduardo Filoni ${ }^{1,2 *}$, Fátima F Fitz ${ }^{2}$, Alexandre Silva ${ }^{3}$ and José M Filho ${ }^{1}$ \\ ${ }^{1}$ Department of Science of Health, State University of Campinas (Universidade Estadual de Campinas), Brazil \\ ${ }^{2}$ Departament of Physcal Therapy, University of Mogi das Cruzes (Universidade de Mogi das Cruzes), Brazil \\ ${ }^{3}$ Departament of Physcal Therapy, Cruzeiro do Sul University (Universidade Cruzeiro do Sul), Brazil
}

Submission: March 15, 2018; Published: May 24, 2018

*Corresponding author: Eduardo Filoni, Department of Science of Health, State University of Campinas (Universidade Estadual de Campinas), Campinas, SP, Avenida Milton 180, Vila Galvão, Guarulhos-SP, CEP: 07063-120, Brazil, Tel: +55 (11) 996299437; Fax: +55 (11) 23585954;

Email: edufiloni@hotmail.com

\begin{abstract}
The object of the study was to evaluate the prevalence, reliability and severity of symptoms of urinary incontinence (UI) in adolescent female soccer players and the impact of those symptoms on quality of life. The present work is a cross-sectional study of 59 female adolescents divided into a group of athletes (35) and control group (24). The International Consultation on Incontinence Questionnaire -Short Form (ICIQ-SF), the pad test and King's Health Questionnaire (KHQ) were used for evaluation. The athletes displayed $62.8 \%$ positivity the pad test and the ICIQ-SF, whereas the control group exhibited $25 \%$ positivity. In terms of quality of life, the athletes exhibited a score of 35.2 in the General Health domain, 37.3 in the Emotions domain and 26.5 in the Sleep/Energy domain. In the present study, a high prevalence of UI symptoms was found in soccer athletes, with moderate reliability between the pad test and the ICIQ-SF; mild UI was found in both groups.
\end{abstract}

Keywords: Therapy; Mindfulness; Yoga; Mindfulness; Nonself, Ethics

\section{Introduction}

Urinary incontinence (UI) is defined by the International Continence Society (ICS) as any involuntary loss of urine. Specifically, one of the symptoms is stress urinary incontinence (SUI), which is the involuntary loss of urine while coughing or sneezing or during physical exercise [1].

In terms of risk factors for UI, women who have had a vaginal delivery exhibit an approximately six times higher probability of UI compared with nulliparous women [2]. However, although vaginal delivery is one of the greatest risk factors for the development of UI, a high prevalence has also been shown among young and nulliparous women [3-5].

A review of the literature showed a UI prevalence of $28 \%$ to $80 \%$ among participants in high-impact sports, such as artistic gymnastics, hockey and ballet [6]. There is no doubt that physical exercise has diverse beneficial effects on health; however, there is evidence that high-impact sports can result in an alteration of intra-abdominal pressure that affects the pelvic organs, thus inducing SUI during sports training or competitions $[7,8]$.
Bo [9] and Eliasson et al. [10] have evaluated the prevalence of UI among artistic gymnasts, dancers and trampolinists, observing a higher prevalence of UI in sports activities that are considered to have a high impact on the pelvic floor compared with low-impact activities.

Full diagnosis involves a variety of procedures ranging from anamnesis to specific UI-evidencing tests. Anamnesis and medical history reflect the patient-reported symptoms. The physical exam allows muscular function evaluation via digital palpation or specific equipment, including a pneumatic device and electromyography $[3,11,12]$. Urinary loss can be evaluated with the pad test, which quantifies leakage in stress situations and the severity of urinary symptoms $[1,13,14]$. The one-hour pad test, which is validated by the ICS, classifies a loss of 1.1 to $9.9 \mathrm{~g}$ as mild, a loss of 10 to $49.9 \mathrm{~g}$ as moderate and losses greater than $50 \mathrm{~g}$ as severe [1].

Questionnaires can be used to detect and measure UI's negative and comprehensive interference with the woman's 
health, which triggers restrictions in the sexual, domestic, occupational and social domains, the latter of which includes physical and/or sports activities [8]. Among the most often used questionnaires are the Incontinence Quality of Life (I-QoL) questionnaire, the Incontinence Impact Questionnaire -Short Form (IIQ-7) and King's Health Questionnaire (KHQ) [15].

Considering the growing number of female athletes who play soccer, a high-impact activity, and the lack of epidemiologic studies in the literature that evaluate UI in soccer, the objective of the present study was to evaluate the prevalence, reliability and severity of UI symptoms among adolescent female soccer players and the impact of UI symptoms on quality of life.

\section{Methods}

\section{Participants}

A cross-sectional study was performed with 59 female soccer players and non-soccer players aged between 11 and 19 years. Participants were included if they were nulliparous, nonpregnant adolescent soccer players and adolescents who did not practice any sports. Adolescents who did not agree or did not obtain permission from their guardian to participate in this study were excluded. The adolescents were recruited and divided into two groups: a group of athletes, composed of 35 amateur soccer athletes, and a control group, composed of 24 adolescents who did not practice any sports. All of the participants' guardians signed the informed consent form according to the Resolution $196 / 96$ of the National Health Council. The project has been approved by the Research Ethics Committee (283.986).

\section{Procedures}

Personal data were collected using a standard form for sample characterization. Subsequently, the International Consultation on Incontinence Questionnaire (ICIQ-SF) was administered to evaluate UI severity by qualifying and quantifying urinary loss. The questionnaire is composed of four questions that evaluate the frequency, severity and impact of UI, plus a set of eight selfdiagnosis items related to the UI causes or situations that the patients have experienced. The ICIQ-SF score is based on the sum of the scores of questions 3,4 and 5 and is classified as follows: mild UI, 1 to 5 points; moderate UI, 6 to 12 points; severe UI, 13 to 18 points; and very severe UI, 19 to 21 points [16].

As a further tool for evaluating the prevalence and severity of urinary loss, the one-hour pad test, standardized by the ICS, was used [17]. All of the athletes took the test at a set time and date before they began their training. One day prior to the test, the participants received a kit containing a bottle with $500 \mathrm{ml}$ of water at room temperature, a sanitary pad that had been previously weighed with an electronic precision-weighing balance (Shimadzu BL3200H) and instructions on the activities they would perform. On the day of the test, the athletes were instructed to urinate two hours before performing the test. They were then instructed to wear the sanitary pad and subsequently ingest $500 \mathrm{ml}$ of water within $15 \mathrm{~min}$. During the subsequent $30 \mathrm{~min}$, the participants performed the following exercise protocol: walk and jog for $15 \mathrm{~min}$; sit down and stand up 10 times; cough 10 times; pick up objects from the floor for $1 \mathrm{~min}$; run on the same spot for $1 \mathrm{~min}$; and, finally, wash hands for $1 \mathrm{~min}$. After the exercises, the sanitary pad was immediately removed. According to ICS recommendations, individuals who exhibit leakage of up to $1 \mathrm{~g}$ are considered continent; hence, the pad test was considered positive when the final weight of the sanitary pad exhibited a 1.1-g urinary loss [1]. After urinary loss was assessed with the pad test, the Brazilian version of the KHQ was administered. The KHQ consists of 30 questions divided into nine domains: health perception, incontinence impact, role limitations, physical limitations, social limitations, personal relationships, emotions, sleep/energy and severity measures. All of the answers are assigned numeric scores, which are added up and evaluated by domain. The values are then calculated using a mathematical formula to obtain the quality of life score, which varies from 0 to 100 , with higher scores representing worse quality of life [18].

\section{Statistical Analysis}

First, the data were tabulated and analyzed using simple descriptive statistical analysis. Student's t test was performed to assess the differences in UI symptoms and quality of life between the athletes and the control group. Fisher's exact test was used to compare the positivity of urinary symptoms between the groups.

Considering the two variables used for the UI observation (the pad test and ICIQ-SF), Cohen's kappa coefficient was used to assess agreement; values above 0.75 represent excellent agreement, values below 0.40 indicate low agreement, and values between 0.40 and 0.75 indicate moderate agreement. The correlation of the variables age, training frequency and time of training with respect to the ICIQ-SF score was assessed using Pearson's correlation test. Values between zero and 0.39 were considered weak correlation, values between 0.40 and 0.69 were considered moderate correlation, and values between 0.7 and 1.0 were considered strong correlation. All statistical analyses were performed with $\alpha<0.05$, and the statistics software packages PASW statistics 18.0 and Excel 2010 were used.

\section{Results}

The sample was composed of a group of athletes that included 35 adolescent amateur soccer players aged 12 to 19 years (15.6 \pm 2.0$)$ with a body mass index (BMI) between 12.4 and $25.9 \mathrm{Kg} / \mathrm{m} 2(20.9 \pm 2.2)$, and a control group of 24 adolescents not practicing any sport and aged 11 to 19 years $(14.8 \pm 2.4)$ with a BMI between 16.4 and $24.7 \mathrm{Kg} / \mathrm{m}^{2}(20.4 \pm 2.68)$. There was a statistically significant difference between the groups for the variable age $(\mathrm{p}=0.008)$.

Table 1 displays the social and urinary characteristics of the athletes and the control group. The athletes had practiced their sport for between six and nine years $(3.1 \pm 2.6)$, performing 
two to five weekly trainings $(3.1 \pm 1.3)$ with an average workload of $(3.1 \pm 0.8)$ hours of training per week. Table 2 itemizes the prevalence of UI in the evaluated groups. Specifically, the athletes exhibited $62.8 \%$ positivity for both tests (the pad test and the ICIQ-SF), whereas the control group exhibited 25\%. There was a statistically significant difference between the groups using both evaluation tools ( $\mathrm{p}=0.007$ ). The degree of agreement between the pad test and the ICIQ-SF was assessed using Cohen's kappa coefficient and was classified as moderate agreement (0.45) (Table 3).

Table 1: Data on the frequency of social and urinary characteristics of the athletes and the control group.

\begin{tabular}{|c|c|c|}
\hline $\begin{array}{c}\text { Social } \\
\text { Characteristics }\end{array}$ & Athletes $(\mathrm{N}=35)(\%)$ & $\begin{array}{c}\text { Control Group } \\
(\mathrm{N}=24)(\%)\end{array}$ \\
\hline \multicolumn{3}{|c|}{ Education } \\
\hline $\begin{array}{l}\text { Elementary school } \\
\text { complete }\end{array}$ & 68.6 & 91.7 \\
\hline $\begin{array}{l}\text { Elementary school } \\
\text { incomplete }\end{array}$ & 31.4 & 8.3 \\
\hline $\begin{array}{c}\text { Urinary } \\
\text { Characteristics }\end{array}$ & Athletes $(\mathrm{N}=35)(\%)$ & $\begin{array}{c}\text { Control Group } \\
(\mathrm{N}=24)(\%)\end{array}$ \\
\hline \multicolumn{3}{|c|}{ Knowledge about UI } \\
\hline No & 88.6 & 75 \\
\hline Yes & 11.4 & 25 \\
\hline \multicolumn{3}{|c|}{ Bladder Pain } \\
\hline No & 68.6 & 75 \\
\hline Yes & 31.4 & 25 \\
\hline \multicolumn{3}{|c|}{ Urinary Infection } \\
\hline No & 62.9 & 41.7 \\
\hline Yes & 37.1 & 58.3 \\
\hline
\end{tabular}

Table 2: Evaluation of the prevalence of urinary incontinence in the athletes and the control group.

\begin{tabular}{|c|c|c|c|c|c|}
\hline $\begin{array}{c}\text { Evaluation } \\
\text { Scale }\end{array}$ & \multicolumn{2}{|c|}{ Athletes } & \multicolumn{2}{c|}{ Control Group } & p Value \\
\hline & N & \% & N & \% & \\
\hline ICIQ-SF & 22 & 62.8 & 6 & 25 & $0.007^{\text {a }}$ \\
\hline Pad test & 22 & 62.8 & 6 & 25 & $0.007^{\mathrm{a}}$ \\
\hline
\end{tabular}

aFisher's exact test

ICIQ-SF: International Consultation on Incontinence QuestionnaireShort Form

Table 3:Assessment of the agreement between the evaluation scales (the ICIQ-SF and the pad test) for the prevalence of urinary incontinence.

\begin{tabular}{|c|c|c|c|c|}
\hline \multirow{2}{*}{ Agreement Between the Scales } & \multicolumn{2}{|c|}{ Pad Test } & \multirow{2}{*}{ Total } \\
\cline { 3 - 4 } & Negative & Positive & \\
\hline ICIQ-SF & Continent & 23 & 8 & 31 \\
\hline & Incontinent & 8 & 20 & 28 \\
\hline \multicolumn{2}{|c|}{ Total } & 31 & 28 & 59 \\
\hline
\end{tabular}

Cohen's kappa coefficient $=0.45$.
The severity of urinary loss was measured using the ICIQ-SF and the one-hour pad test. According to the severity classification based the ICIQ-SF, mild UI (from 1 to 5 points) could be observed in both for the athletes group, which exhibited an average score of $3.2( \pm 3.2)$, and for the control group, which had an average score of $2.0( \pm 3.6)$. There was a statistically significant difference between the groups $(\mathrm{p}=0.027)$. For the pad test, the athletes exhibited an average urinary loss of $1.7 \mathrm{~g}( \pm 0.7 \mathrm{~g})$, whereas the average urinary loss of the control group was $2.1 \mathrm{~g}( \pm 0.8 \mathrm{~g})$. There was no statistically significant difference between the groups ( $p$ $=0.309$ ).

A moderate correlation ( $r=0.45$ ) between age and urinary loss was observed among the athletes. Regarding the correlation between the frequency of weekly training or the time of training in years and the severity of urinary loss, as assessed by the ICIQ-SF, the athletes exhibited a moderate correlation for the frequency of weekly training $(r=0.44)$ and a weak correlation with time of training $(r=0.34)$. There was no correlation between the variables age, time of training or frequency of training and the severity of urinary loss, as assessed by the one-hour pad test.

Regarding quality of life, the athletes exhibited an average score of $35.2( \pm 22.7)$ in the General Health domain compared with an average score of $20.8( \pm 18.8)$ for the control group. Further, the control group exhibited a higher average score compared with the athletes in the domains Incontinence Impact, Physical Limitations, Emotions, Sleep/Energy and Severity Measures.

Table 4: Comparison of the scores of the KHQ domains between incontinent individuals in the athletes group and the control group.

\begin{tabular}{|c|c|c|c|}
\hline Domain & $\begin{array}{c}\text { Athletes }(\mathrm{N}=22) \\
\text { Mean }( \pm \mathrm{SD})\end{array}$ & $\begin{array}{c}\text { Control Group } \\
(\mathrm{N}=6) \text { Mean }( \pm \mathrm{SD})\end{array}$ & p Value \\
\hline General Health & $35.2( \pm 22.7)$ & $20.8( \pm 18.8)$ & 0.14 \\
\hline $\begin{array}{l}\text { Incontinence } \\
\text { Impact }\end{array}$ & $19.7( \pm 19.6)$ & $27.7( \pm 13.6)$ & 0.27 \\
\hline $\begin{array}{c}\text { Role } \\
\text { Limitations } \\
\end{array}$ & $18.1( \pm 24.6)$ & $2.78( \pm 6.8)$ & $0.01^{*}$ \\
\hline $\begin{array}{l}\text { Physical } \\
\text { Limitations }\end{array}$ & $18.1( \pm 15.3)$ & $19.44( \pm 6.8)$ & 0.77 \\
\hline $\begin{array}{c}\text { Social } \\
\text { Limitations } \\
\end{array}$ & $4.04( \pm 8.7)$ & $1.87( \pm 2.8)$ & $0.04^{*}$ \\
\hline $\begin{array}{c}\text { Personal } \\
\text { Relationships }\end{array}$ & $4.44( \pm 9.89)$ & $6.67( \pm 9.12)$ & 0.65 \\
\hline Emotions & $37.3( \pm 14.7)$ & $50( \pm 13.6)$ & 0.08 \\
\hline Sleep/Energy & $26.5( \pm 13.2)$ & $47.2( \pm 16.3)$ & $0.02 *$ \\
\hline $\begin{array}{l}\text { Severity } \\
\text { Measures }\end{array}$ & $14.7( \pm 12.3)$ & $27.7( \pm 11.3 .3)$ & 0.04 \\
\hline
\end{tabular}

${ }^{*} p<0.05$

Regarding the impact of urinary symptoms on the quality of life, as assessed with the KHQ, Student's t test revealed a statistically significant difference between the athletes and the control group on all domains with the exception of General 
Health $(\mathrm{p}=0.14)$, Incontinence Impact $(\mathrm{p}=0.27)$ and Personal Relationships ( $\mathrm{p}=0.65$; Table 4 ).

\section{Discussion}

The results of the present study reveal a $62 \%$ prevalence of UI symptoms among adolescent nulliparous soccer athletes. In a review of the literature, a $28 \%$ to $80 \%$ prevalence of UI could be observed among participants in high-impact sports, such as artistic gymnastics, hockey and ballet [6]. The authors Bo [9] and Eliasson et al. [10] evaluated the prevalence of UI among artistic gymnasts, dancers and trampolinists and observed a higher prevalence of UI in sports disciplines that are considered to have a high impact on the pelvic floor compared with lowimpact sports. Although these studies did not use the same methodology or sampling and examined sports, both studies point to a UI prevalence above $54 \%$ among the athletes.

In the present study, the control group exhibited a UI prevalence of $25 \%$. Some studies relate the presence of UI to other urinary disorders, such as bladder pain and urinary infection. This could explain the UI prevalence in the control group, given that urinary infection and bladder pain was observed in $58.3 \%$ and $25 \%$ of the adolescents, respectively.

The ICS emphasizes that UI must be demonstrated objectively, which is possible using the one-hour pad test Specifically, this test evaluates the presence of UI and quantifies the severity of urinary symptoms [1]. In the present survey, the prevalence and severity of UI were evaluated using the onehour pad test and the ICIQ-SF. As stated above, the pad test is very specific in its evaluation of the presence and severity of UI, whereas evaluation based on questionnaires requires careful interpretation of the results. There was a statistically significant difference between groups in the ICIQ-SF evaluation; the athletes exhibited higher severity ( $p=0.027$ ). The pad test evaluation, however, exhibited no statistically significant difference between the groups ( $p=0.309$ ). Bo \& Sundgot Borgen [19] found the SUI symptoms in $41 \%$ of the elite athletes who were evaluated using a questionnaire. Another study of young nulliparous physical education students showed an SUI prevalence of 38\% according to a questionnaire, and six of the seven students who underwent urodynamic evaluation exhibited sphincter incompetence [5].

The factors that contribute to UI in young and nulliparous women are not yet fully elucidated. Weak connective tissue, combined with high-intensity and high-impact activities, may contribute to this condition [20]. Bo \& Sundgot Borgen [4] reported an increased prevalence of athletes with UI and a relationship with eating disorders. This association between UI and eating disorders may arise because eating disorders cause a lack of appropriate nutrients, which in turn favors the reduction of the strength and resistance of the pelvic floor muscles. The agreement between the pad test results and those of the ICIQ-SF in evaluating the prevalence of UI was assessed using Cohen's kappa coefficient. A moderate agreement $(0.45)$ between the applied evaluation scales could be observed.
Franco et al. [21] found that the ICIQ-SF is easy to administer and that there is a good agreement between this questionnaire and the one-hour pad test results for women with UI. The two tests incorporate both the severity of symptoms and the quality of life variables; thus, we recommend using these tests as a routine procedure in clinical practice. Pereira et al. [22] have used the pad test as a comparative tool to validate an evaluation questionnaire specific for UI called the Incontinence Severity Index (ISI); the researchers found satisfactory reliability, internal consistency, reproducibility and validity, indicating agreement between the pad test and the ISI. Liebergall Wischnitzer et al. [23] demonstrated agreement between the pad test results and a subjective evaluation questionnaire for UI, using it as a complementary tool to evaluate UI severity.

In the present study, we hypothesized that age, time and weekly hours and frequency of training were correlated with UI severity. According to the ICIQ-SF, the correlation between age or the frequency of weekly training and UI severity in the athletes was moderate, with $r=0.45$ and $r=0.44$, respectively, whereas the correlation with the time of training in years was weak, with $\mathrm{r}=0.34$.

Eliasson et al. [10] have associated time, duration and frequency of training with the presence of urinary symptoms. According to the authors, the longer the time, duration and frequency of training, the higher the prevalence of UI in athletes practicing high-impact sports. As opposed to the present study's findings with respect to the correlation between age and UI, the studies by Bo [9] and Eliasson et al. [10] revealed no statistically significant correlation between age and UI.

Knowledge about the perineal region and the dysfunctions that can afflict it is a basis for a good treatment performance and preventing dysfunctions [3]. In the present study, approximately $88 \%$ and $75 \%$ of young nulliparous women in the athletes group and the control group, respectively, were knowledgeable about UI symptoms. The level of education favors these findings, given that the majority of the studied population had completed elementary school, i.e. approximately $68 \%$ of the athletes and $91 \%$ of the control group.

According to some studies, women with UI report physical limitations, such as restrictions in practicing sports and carrying objects, and changes in social, occupational and domestic activities that negatively influence their emotional state and sex life. Further, UI can provoke social and hygienic discomfort related to the fear of urinary loss, the smell of the urine, the need to use protection (sanitary pads) and the more frequent need to change clothes $[24,25]$. Incontinent athletes avoid ingesting liquid prior to trainings and competitions, which ultimately affects body hydration, a fact that must receive special attention to avoid health problems [6].

Numerous tools have been used to evaluate the impact of UI on the quality of life of affected women. In the present study, quality of life was evaluated using the KHQ, which has 
been translated and adapted into Portuguese [18]. Regarding the General Health domain, the athletes exhibited an average score of $35.2( \pm 22.7)$, and the control group exhibited an average score of 20.8 ( \pm 18.8 ). For the domains Incontinence Impact, Physical Limitations, Social Limitations, Emotions, Sleep/Energy and Severity Measures, the control group exhibited a higher average score than the athletes did.

The low impact on quality of life observed here could be explained by the fact that the severity of urinary symptoms was relatively low. According to Jácome et al. [26], urinary incontinence negatively influences quality of life and has a negative impact on sports performance. Ree et al. [27] affirmed that young nulliparous women exhibit a $17 \%$ reduction of the mean maximum voluntary contraction after 90 min of strenuous exercise, indicating muscular fatigue of the pelvic floor and showing the importance of specific training for these muscles.

Structural and functional changes can occur in the lower urinary tract over the course of these women's lives because of the risk factor exposure to which they submit themselves. As mentioned above, these changes can lead to the development of urinary symptoms, including UI. Thus, it is of paramount importance to assess the risk factors and study the prevalence of symptoms in a particular population, such as adolescent soccer players, to allow for a preventive gynecological evaluation and the development of sensory-motor training and pelvic floor awareness programs to prevent or minimize the symptoms in the future.

\section{Conclusion}

The present study shows a high prevalence of UI symptoms among athletes, with medium reliability between the ICIQ-SF and the pad test as assessed using Cohen's kappa coefficient. Mild SUI was observed in both groups, as assessed by the pad test and the ICIQ-SF. In terms of quality of life, the domains General Health, Emotions and Sleep/Energy, which are considered to have the highest impact on the quality of life, had the highest scores among the athletes.

\section{References}

1. Abrams P, Cardozo L, Fall M, Griffiths D, Rosier P, et al. (2002) The standardisation of terminology in lower urinary tract function: Report from the standardisation sub-committee of the international continence society. Urology 61(1): 37-49.

2. Timur Taşhan S, Beji NK, Aslan E, Yalçin Ö (2012) Determining lower urinary tract symptoms and associated risk factors in young women. Int J Gynaecol Obstet 118(1): 27-30.

3. Bø K, Sherburn M (2005) Evaluation of female pelvic floor muscle function and strength. Phys Ther 85(3): 269-282.

4. Bø K, Sundgot Borgem J (2001) Prevalence of stress and urge urinary incontinence in elite athletes and controls. Med Sci Sports Exerc 33(11): 1797-1802

5. Bø K, Stien R, Kulseng Hanssen S, Kristofferson M (1994) Clinical and urodynamic assessment of nulliparous young women with and without stress incontinence symptoms: A case control study. Obstet Gynecol 84(6): 1028-1032.
6. Goldstick 0, Constantini N (2013) Urinary incontinence in physically active women and female athletes. Br J Sports Med 48(4): 296-298.

7. Jiang K, Novi JM, Darnell S, Arya LA (2004) Exercise and urinary incontinence in women. Obstet Gynecol Surv 59(10): 717-721.

8. Papanicolaou S, Hunskaar S, Lose G, Sykes D (2005) Assessment of bothersomeness and impact on quality of life of urinary incontinence in women in France, Germany, Spain and the UK. BJU Int 96(6): 831838.

9. $\mathrm{B} \emptyset \mathrm{K}(2004)$ Urinary incontinence pelvic floor dysfunction, exercise and sport. Sports Med 34(7): 451-464.

10. Eliasson K, Larsson T, Mattsson E (2002) Prevalence of stress incontinence in nulliparous elite trampolinists. Scand J Med Sci Sports 12(2): 106-110.

11. Laycock J, Jerwood D (2001) Pelvic floor muscle assessment: the perfect scheme. Physiotherapy 87(12): 631-642.

12. Vodusek DB (2007) Neuroanatomy and neurophysiology of pelvic floor muscles. In: Bo K, Berghmans B, Morkved S, Van Kampen M (Eds.), Evidence based physical therapy for the pelvic floor: bridging science and clinical practice. Elsevier, Edinburgh; New York, USA, pp. 53-63.

13. Lose G, Rosenkilde P, Gammelgaard J, Schroeder T (1998) Padweighing test performed with standardized bladder volume. Urology 32(1): 78-80

14. Milani R, Valli G, Bhole MV (1992) Yoga-eutonia in genuine stress incontinence -an exploratory study. Yoga Mimamsa Journal 30(4): 1020.

15. Kwon BE, Kim GY, Son YJ, Roh YS, You MA (2010) Quality of life of women with urinary incontinence: a systematic literature review. Int Neurourol J 14(3): 133-138.

16. Tamanini JT, Lebrão ML, Duarte YA, Santos JL, Laurenti R (2009) Analysis of the prevalence of and factors associated with urinary incontinence among elderly people in the municipality of São Paulo, Brazil: SABE study (health, wellbeing and aging). Cad Saude Publica 25(8): 1756-1762.

17. Twiss CO, Fischer MC, Nitti VW (2007) Comparison between reduction in 24-hour pad weight, international consultation on incontinenceshort form, score, international prostate symptom score, and postoperative patient global impression of improvement score in patient evaluation after male perineal sling. Neurourol Urodyn 26(1): 8-13.

18. Fonseca ESM, Camargo ALM, Castro RA, Sartori MGF, Fonseca MCM, et al. (2005) Validação do questionário de qualidade de vida (King's Health Questionnaire) em mulheres brasileiras com incontinência urinária [Validation of a quality of life questionnaire (King's Health Questionnaire) in Brazilian women with urinary incontinence]. Revista Brasileira de Ginecologia e Obstetrícia: Revista da Federação Brasileira das Sociedades de Ginecologia e Obstetrícia 27(5): 235-242.

19. Bø K, Sundgot Borgen J (2010) Are former female elite athletes more likely to experience urinary incontinence later in life than non athletes? Scand J Med Sci Sports 20(1): 100-104.

20. Nygaard IE, Thompson FL, Svengalis SL, Albright JP (1994) Urinary incontinence in elite nulliparous athletes. Obstet Gynecol 84(2): 183187.

21. Franco AV, Lee F, Fynes MM (2008) Is there an alternative to pad tests? Correlation of subjective variables of severity of urinary loss to the 1-h pad test in women with stress urinary incontinence. BJU Int 102(5): 586-590.

22. Pereira VS, Santos JYC, Correia GN, Driusso P (2011) Tradução e validação para a língua portuguesa de um questionário para avaliação da gravidade da incontinência urinária [Translation and validation into Portuguese of a questionnaire to evaluate the severity of urinary incontinence]. Revista Brasileira de Ginecologia e Obstetrícia: Revista 
da Federação Brasileira das Sociedades de Ginecologia e Obstetrícia 33(4): 182-187

23. Liebergall Wischnitzer M, Paltiel O, Hochner Celnikier D, Lavy Y, Shveiky D, et al. (2010) Concordance between one-hour pad test and subjective assessment of stress incontinence. Urology 76(6): 13641368.

24. Kelleher C (2000) Quality of life and urinary incontinence. Baillieres Best Pract Res Clin Obstet Gynaecol 14(2): 363-379.

25. Saleh N, Bener A, Khenyab N, Al Mansori Z, Al Muraikhi A (2005) Prevalence, awareness and determinants of health care-seeking behaviour for urinary incontinence in Qatari women: a neglected problem? Maturitas 50(1): 58-65

26. Jácome C, Oliveira D, Marques A, Sá Couto P (2011) Prevalence and impact of urinary incontinence among female athletes. Int J Gynaecol Obstet 114(1): 60-63.

27. Ree ML, Nygaard I, Bø K (2007) Muscular fatigue in the pelvic floor muscle after strenuous physical activity. Acta Obstet Gynecol Scand 86(7): 870-876.

Your next submission with Juniper Publishers
will reach you the below assets
- Quality Editorial service
- Swift Peer Review
- Reprints availability
- E-prints Service
- Manuscript Podcast for convenient understanding
- Global attainment for your research
- Manuscript accessibility in different formats
( Pdf, E-pub, Full Text, Audio)
- Unceasing customer service
ack the below URL for one-step submission
https://juniperpublishers.com/online-submission.php

